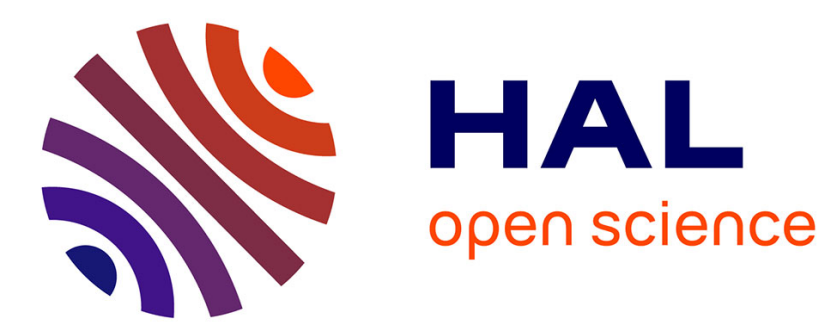

\title{
La sorcière et ses avatars dans le répertoire romantique et postromantique
}

\author{
Hélène Laplace-Claverie
}

\section{To cite this version:}

Hélène Laplace-Claverie. La sorcière et ses avatars dans le répertoire romantique et postromantique. Repères, cahier de danse, 2012, 30, pp.5-8. hal-02171640

\section{HAL Id: hal-02171640 \\ https: / hal-univ-pau.archives-ouvertes.fr/hal-02171640}

Submitted on 20 Nov 2020

HAL is a multi-disciplinary open access archive for the deposit and dissemination of scientific research documents, whether they are published or not. The documents may come from teaching and research institutions in France or abroad, or from public or private research centers.
L'archive ouverte pluridisciplinaire HAL, est destinée au dépôt et à la diffusion de documents scientifiques de niveau recherche, publiés ou non, émanant des établissements d'enseignement et de recherche français ou étrangers, des laboratoires publics ou privés. 


\section{La sorcière et ses avatars dans le répertoire romantique et postromantique}

Dès l'âge baroque, et jusqu'à la fin du XVIII ${ }^{\mathrm{e}}$ siècle, ballets et divertissements d'opéra mettent volontiers à l'honneur furies, démons, sorciers et autres figures grimaçantes d'inspiration plus ou moins mythologique. Mais c'est à l'époque romantique que le personnage médiéval de la sorcière conquiert véritablement les scènes chorégraphiques. Ainsi, en 1829, La Belle au bois dormant d'Aumer, sur un livret du dramaturge Eugène Scribe, donne à la « mauvaise fée » des résonances diaboliques en accord avec la sensibilité du temps. Mais l'on pourrait citer bien d'autres exemples de la séduction qu'exerce alors ce mythe féminin.

Comme le prouve en 1862 la publication par Michelet d'un livre qui lui est consacré, la sorcière retrouve au $\mathrm{XIX}^{\mathrm{e}}$ siècle une actualité dont les milieux artistiques se font l'écho. Il faut dire que le motif est riche à la fois de résonances symboliques et d'un indéniable potentiel spectaculaire. Pierre Larousse, dans son fameux Grand Dictionnaire universel du XIX siècle, ne définit-il pas les fées comme des survivances des antiques Parques - ces maitresses des destins humains - et les sorcières comme le produit de la condamnation par l'Eglise chrétienne de ces mêmes fées, jugées coupables de faire allégeance au paganisme ? A l'origine, dans la littérature médiévale, point de différence entre fées et sorcières : toutes traduisent un certain rapport à la nature et à la féminité ; toutes incarnent le rejet de l'ordre social et moral. Ce n'est qu'au fil du temps qu'apparaît le clivage entre bonnes fées et méchantes sorcières, tel qu'on le retrouvera par exemple en 1890 dans La Belle au bois dormant de Petipa. L'image devenue archétypale de la sorcière - une vieille femme repoussante - est une invention moderne, liée à la récupération folklorique du personnage.

Art volontiers manichéen, le ballet ne pouvait que se satisfaire de cette simplification. D'autant qu'à l'époque romantique, librettistes et chorégraphes sont friands de thèmes surnaturels. Comme l'a souligné Théophile Gautier, les ballets romantiques se caractérisent d'abord par le choix de sujets relevant, non plus du merveilleux mythologique comme c'était le cas aux XVII ${ }^{\mathrm{e}}$ et XVIII $\mathrm{e}^{\mathrm{e}}$ siècles, mais de la littérature fantastique: "A dater de La Sylphide, Les Filets de Vulcain, Flore et Zéphyr ne furent plus possibles ; l'Opéra fut livré aux gnomes, aux ondins, aux salamandres, aux Elfes, aux Nixes, aux Wilis, aux Péris et à tout ce peuple étrange et mystérieux qui se prête si merveilleusement aux fantaisies du maître de ballet. ${ }^{1}$ ' Si la sorcière n'apparaît pas dans l'énumération proposée par Gautier, c'est sans doute qu'elle est un être hybride, qui appartient à la fois au monde réel et à l'univers onirique, à l'humanité et à la sphère démoniaque.

Or l'un des spectacles fondateurs de l'esthétique romantique au théâtre fut en 1831 l'opéra de Meyerbeer Robert le Diable, dont le célèbre «Ballet des Nonnes» fascina durablement les contemporains. Cet intermède chorégraphique met en scène des spectres de religieuses dansant une sorte de bacchanale effrénée. Religion, subversion, atmosphère macabre, féminité paradoxale : ces différents éléments seront par la suite constitutifs des personnages de sorcières qui peupleront les ballets romantiques. A commencer par La Sylphide, chorégraphié en 1832 par Philippe Taglioni pour sa fille Marie, sur un livret du ténor Adolphe Nourrit, lequel avait interprété quelques mois plus tôt le rôle principal de Robert le Diable. S'inspirant librement d'un conte de Charles Nodier, Nourrit imagine l'histoire d'un jeune Ecossais tiraillé entre son amour pour sa fiancée et l'attirance qu'exerce sur lui une mystérieuse créature immatérielle. Mais une troisième figure féminine joue un rôle fondamental. Pour augmenter la tension dramatique, le librettiste de La Sylphide a en effet ajouté un personnage de sorcière, absent du texte de Nodier. Madge - c'est le nom du personnage - s'oppose par son âge et sa laideur aux deux jeunes femmes séductrices qui se partagent le cœur de James. Mais elle symbolise aussi une sorte de passerelle entre Effie et son aérienne rivale : comme la première, elle appartient au monde des humains ; mais elle est dotée, à l'instar de la seconde, de pouvoirs surnaturels. C'est donc au centre d'un triangle féminin très symbolique qu'est pris au piège le protagoniste. Et ce que l'art du ballet ne peut dire avec des mots, il le donne à voir au moyen de langages chorégraphiques différents : fille de la terre, Effie exécute des danses d'inspiration folklorique, tandis que l'aérienne Sylphide se distingue par un style fait de légèreté et d'élévation. Quant à la sorcière Madge, émanation des profondeurs infernales, elle ne danse pas mais s'exprime par le truchement de la pantomime.

\footnotetext{
1 Théophile Gautier, La Presse, $1^{\text {er juillet } 1844 .}$
} 
C'est la raison pour laquelle ce rôle fut interprété à la création par un homme, ce qui était au demeurant le cas au XIX ${ }^{\mathrm{e}}$ siècle pour tous les personnages grotesques. Cette dernière notion, théorisée par Victor Hugo dans la Préface de Cromwell (1827), est précieuse pour cerner les enjeux dramaturgiques et esthétiques de la sorcière. En dignes héritiers de Shakespeare, les écrivains romantiques cultivent dans leur théâtre les contrastes et les chocs de registre. Mais c'est sans doute moins les oppositions manichéennes qui les intéressent, que les miroitements de l'ambiguiité. Or, dans ce contexte, la sorcière n'est pas seulement un nécessaire contrepoint, le versant ténébreux de personnages idéalisés; elle est l'un des visages de ces mondes invisibles qui attirent l'être humain, tantôt pour le mener à sa perte, tantôt pour assurer son salut.

C'est en cela qu'au-delà des figures effectivement identifiables comme des sorcières, il est possible d'annexer à cette catégorie des personnages a priori différents, telles les fameuses Wilis de Giselle (1841). Henri Heine, à qui Théophile Gautier emprunta le sujet de son ballet, les décrit dans son ouvrage De l'Allemagne (1834) comme des "Bacchantes mortes». La filiation est évidente avec les nonnes spectrales de Robert le Diable; et la gracieuse apparence de ces blancs fantômes aux gestes délicats ne doit pas égarer le spectateur. Ce sont des furies ivres de vengeance, des juges cruels et sans pitié qu'affronte le malheureux Hilarion dans une scène célèbre du ballet, au cours de laquelle l'imprudent jeune homme est mis à mort par ses ennemies. Et sans doute la magie du spectacle est-elle d'autant plus forte que les puissances infernales se dissimulent ici sous le masque de la beauté et de l'élégance.

Mais d'autres masques sont envisageables, et les auteurs de ballet ne manquent pas d'imagination en la matière. Pour ne parler que d'œuvres restées au répertoire, il serait tentant de voir dans le Coppélius de Coppélia (1870) et dans le Drosselmeier de Casse-Noisette (1892) deux avatars de la figure du sorcier. S'agissant de Coppélia, il faut rappeler que si le livret de Nuitter édulcore sensiblement le récit d'Hoffmann qu'il prétend adapter, le personnage du fabricant d'automates n'est pas dénué de traits fantastiques. Sorte de Pygmalion moderne, le vieux savant rêve de donner vie aux créatures artificielles qu'il cache dans son atelier. D'emblée ce dernier s'apparente à l'antre de quelque démon, ou à la grotte de quelque sorcière : les fenêtres en sont grillées, l'accès en est interdit. Et lorsque Swanilda et ses compagnes s'introduisent dans la mystérieuse demeure à l'acte II, le propriétaire des lieux vient tout à coup les surprendre « comme s'il sortait de terre ${ }^{2}$ », avant d'ouvrir son livre de magie et de se livrer à des « conjurations cabalistiques ${ }^{3}$ ». L'alchimie, le magnétisme ainsi que les sciences occultes reviennent à la mode au XIX ${ }^{\mathrm{e}}$ siècle, dans la société comme dans la littérature, et constituent autant de sources d'inspiration pour les chorégraphes. En 1854, Théophile Gautier avait par exemple mis un personnage de magnétiseur au centre de son ballet Gemma, modernisant de la sorte le stéréotype médiéval du sorcier. La démarche est à peu près la même dans le CasseNoisette de Petipa, où l'oncle de la petite Clara fait figure d'intermédiaire entre le monde rationnel des adultes et l'univers enchanté de l'enfance. On est certes très loin des sorcières de Macbeth et de leur chaudron, puisque Drosselmeier a toutes les apparences d'un être policé parfaitement intégré à la société. Mais on peut se demander si le voyage initiatique de Clara dans le monde merveilleux - et néanmoins effrayant - des jouets n'est pas le résultat de quelque sortilège. A moins qu'il ne s'agisse de la transposition d'un rêve (ou d'un cauchemar) de la jeune fille...

On voit quelle interprétation la psychanalyse pourrait faire de ce type d'histoire, tant le fantastique, ici, confine au fantasmatique. Différents ballets relèvent de cette problématique, à commencer par le célèbre Lac des cygnes (1877). Le maléfique Rothbart, responsable de la métamorphose animale de l'hérö̈ne, incarne la part obscure, pulsionnelle de la jeune Odette. Ce qui en elle échappe à la culture et à l'éducation s'exprime dans le personnage du cygne blanc, et plus encore dans son alter ego démoniaque, le cygne noir. La sorcellerie, en l'occurrence, n'est que le révélateur des zones d'ombre d'un personnage féminin plus complexe qu'on pourrait le penser a priori, une sorte de miroir grossissant où se reflètent les ambivalences de la psyché humaine. Et tout le mérite de l'art chorégraphique est de donner une forme concrète, à travers des images et des sons, des gestes, des mélodies, des costumes et des décors, aux tourments de l'âme.

2 Voir le livret de Coppélia, reproduit dans L'Avant-Scène (Ballet/Danse), n4, novembre-janvier 1981, p. 26.

3 Ibid., p. 27. 
A la fin du $\mathrm{XIX}^{\mathrm{e}}$ siècle, nombre de ballets figurant au répertoire de l'Opéra de Paris convoquent le thème du pacte diabolique : pour ne mentionner que deux d'entre eux, chorégraphiés par Mérante, La Korrigane (1880) et La Farandole (1883) orchestrent ce motif, le premier sur fond de légende bretonne, le second dans un cadre provençal. Mais c'est une fois de plus du côté de Marius Petipa que l'on trouve le plus bel exemple de réinvestissement chorégraphique du personnage de la sorcière. Dans La Belle au bois dormant (1890), la Fée Carabosse est en effet l'un des éléments centraux du ballet et son moteur dramatique. Elle est dotée d'attributs grotesques, puisqu'elle apparaît dans une brouette traînée par des rats et flanquée de pages difformes. Mais conformément à la tradition romantique, elle est aussi la toute-puissante représentante des forces du mal. Par ailleurs, à la différence des autres rôles de fée, celui-ci n'est pas dansé mais mimé, et ce par un homme : le grand Enrico Cechetti fut le premier interprète du personnage et inventa une gestuelle éloquente que s'employèrent à imiter ses successeurs. Ironie de l'histoire, quand les Ballets russes montent le spectacle une trentaine d'années plus tard, en 1921 à Londres, c'est Carlotta Brianza, créatrice trente ans plus tôt de la princesse Aurore, qui incarne la redoutable Carabosse. Au-delà de l'anecdote, cette prise de rôle est significative : désormais, les personnages de sorcière ne sont plus l'apanage d'interprètes de sexe masculin. Faut-il y voir un symptôme de revalorisation?

Force est en tout cas de noter que les sorcières restent présentes au $\mathrm{XX}^{\mathrm{e}}$ siècle dans le répertoire chorégraphique. Il est même troublant de constater que le ballet le plus emblématique de la modernité, Le Sacre du printemps (1913), recourt à cette figure féminine. La sorcière n'est-elle pas, à l'image de la chorégraphie de Nijinski et de la partition de Stravinsky, à la fois archaïque et révolutionnaire? Elle incarne la fidélité à une certaine tradition, tout en offrant de nombreuses possibilités d'innovation, par sa plasticité et son caractère énigmatique. Un auteur de ballets ne s'y est pas trompé, qui a su concilier la dimension folklorique du personnage avec sa charge symbolique. Il s'agit de l'écrivain Louis-Ferdinand Céline, qui composa avant et après la Deuxième Guerre mondiale plusieurs arguments chorégraphiques qu'il essaya en vain de faire représenter ${ }^{4}$. Dans ces livrets, le personnage de la sorcière joue à plusieurs reprises un rôle fondamental. Ainsi dans La Naissance d'une fée (1937), le scénariste donne beaucoup d'importance à la "mère Karalik », une "vieille gitane méchante... envieuse sorcière..." qui «sait lire l'avenir dans les lignes de la main... ${ }^{5}$ ». Mais le plus intéressant, dans notre perspective, est sans doute la façon dont l'auteur de Voyage au bout de la nuit reprend certains topoi du ballet romantique. En digne héritier de Théophile Gautier, il imagine la transformation d'une jeune fille en fée, suite à un dépit amoureux. Et exactement comme dans La Sylphide, il confère au motif de la vengeance une place centrale : c'est par jalousie que la sorcière Karalik cause la mort de l'héroïne, avant de se métamorphoser en crapaud.

Dans un autre livret publié la même année, Voyou Paul. Brave Virginie, le héros de Bernardin de Saint-Pierre est envoûté par une sorcière démoniaque qui détient une liqueur susceptible de déclencher chez ceux qui en boivent une frénésie lubrique. Et là encore, les sortilèges fauteurs de troubles entraînent la mort de la pure héroïne. Céline, on le voit, se met à l'école de modèles romantiques qu'il connaît bien, et n'hésite pas à convoquer l'archétype de la sorcière. Cela pourrait surprendre chez un artiste aussi novateur. Il faut peut-être y voir, a contrario, la preuve de l'extraordinaire potentiel dramatique et chorégraphique d'un personnage qui reste au $\mathrm{XX}^{\mathrm{e}}$ siècle une féconde source d'inspiration pour ceux qui continuent de faire vivre l'art du ballet narratif.

\footnotetext{
4 Aussi étrange que cela paraisse, les trois premiers livrets composés par Céline sont insérés dans son pamphlet antisémite, Bagatelles pour un massacre, publié en 1937. Au lendemain de la guerre, il rédige deux autres arguments chorégraphiques. Et en 1959, ces différents textes sont réunis en volume sous le titre Ballets sans musique, sans personne, sans rien.

${ }^{5}$ Cahiers Céline, nº ${ }^{\circ}$, Gallimard, 1988, p. 85.
} 